\title{
Study on Causes and Strategies of Efficacy Sense of college English teachers
}

\author{
Yun Zhou \\ School of Foreign Languages, Yuxi Normal University, Yuxi, 653100, China
}

\begin{abstract}
Keywords: English teacher; efficacy sense; college English teaching
\end{abstract}
\begin{abstract}
Efficacy sense refers to teachers' confidence in their work tasks and concerns teachers' teaching quality. Efficacy sense of English teachers is influenced by many factors, such as students' cooperation, schools' support and their own quality. Improvement of efficacy sense of English teachers can not only boost teaching quality, but also promote the position of English in the hearts of students and create good atmosphere for English teaching. This paper mainly discusses influencing factors of efficacy sense of English teachers and improvement strategies under the typical background of college English teaching.
\end{abstract}

\section{Introduction}

In the face of a series of problems such as the query of college English teaching and connection of CET-4 and CET-6 with academic degree, college English teaching reform has received much attention. College English teaching reform will inevitably give rise to brand-new teaching tasks and objectives. Thus, English teachers are required to adopt new teaching methods. So, teachers must own very strong flexibility, or else it is difficult to achieve implementation of new teaching ideas and teaching objectives. In the face of various kinds of pressure, how do college English teachers accurately find out positioning and quickly adapt challenges caused by course reform? This paper mainly explores opportunities and challenges faced by college English teachers from the perspective of teacher efficacy and influencing factors of teacher efficacy.

\section{Overview of teacher efficacy}

The concept of teacher efficacy is mainly from self-efficacy theory of Bandura ${ }^{[1]}$. Teacher efficacy refers to the confidence in completing teaching tasks perfectly and the ability to make students gain knowledge through their teaching. Teacher efficacy derives from students' feedbacks and in turn influences teaching quality. Teacher efficacy refers to teachers' general views and judgment of the function of education in students' development and the relationship between teaching and learning and reflects educational idea and creed as well as teachers' recognition degree on current educational reform. Individual efficacy of teachers refers to teachers' recognition degree on their own teaching ability. Teacher efficacy is closely related to students' school performance. With different teacher efficacy, the teaching methods and mental attitude shown to students are also different. Naturally, teaching effects are different. The researches of Ashton et al. show teaching efficacy have great influences on students' mathematical achievement, while individual efficacy of teachers greatly influences language-related performance ${ }^{[2]}$. Armor et al. through Rand scale test find teacher efficacy is significantly related to students' scholastic achievement ${ }^{[3]}$. Besides, some researches indicate different teacher efficacy will influence teachers' attitude to teaching reform and changes ${ }^{[4]}$. Teacher efficacy can reflect teaching force of a team and play a great role for students' learning and school development. English serves as a public required course. Efficacy sense of English teachers directly influences popularity of this public course.

\section{Factors influencing efficacy sense of college English teachers}

Colleges regard English as a foundation course for college students, which aims to cater to the important position of English as the first global communication language. Efficacy sense of college English teachers is directly influenced by social acceptance level for English. Of course, in addition 
to this, there are many other influencing factors, such as teachers' specialty accomplishment and cultural accomplishment as well as the degree of schools paying attention to English teaching. Generally, factors influencing efficacy sense of college English teachers can be classified into two aspects: external factors and internal factors.

\subsection{External factors}

External factors refer to those which do not transfer with the will of college English teachers and strongly influence teacher efficacy, such as social environment and learning atmosphere.

\subsubsection{Social environment}

The teacher as an occupation is influenced by social environment. Higher social recognition degree for teacher occupation means teacher occupation receives more respects. Meanwhile, teachers' welfare and salary also increase and teachers' recognition degree for themselves increase, too. For example, in 2008, after the state improved the welfare of primary and middle school teachers, efficacy sense of primary and middle school teachers increased to different degrees ${ }^{[5]}$. Relative to general engineering teachers, college English teachers have no support of scientific research funds. Most of their salary source depends on their teaching quality and quantity. Social attention to English and respect of teachers can boost efficacy sense of college English teachers. At present, although English is still a public foundation course in colleges and international diplomatic language, social attention to it weakens. More and more people pay attention to learning minority languages. College English major is not a hot major currently. So, in present social environment, college English teachers are faced with more challenges.

\subsubsection{School environment}

For college teachers, they spend most of their time in schools. School environment and learning atmosphere influence their teaching feeling. In accordance with the researches of Xin Tao et al. (2004), the following three factors have great influences on teachers' teaching feeling: relationship between students and teachers, school climate and development prospect of educational work. Ashton (1984) through researches draws the following conclusion: school factors influencing teacher efficacy include school atmosphere and teaching facilities. Some investigations also show class size will also influence teaching efficacy. Obviously, if a class is large, the teacher will face more students. Since a teachers' energy is limited, he cannot consider too many students at the same time. This will greatly reduce teaching efficacy. Naturally, teachers' teaching efficacy is low. Generally speaking, school environment imposes great influences on teacher efficacy. This is an objective factor. It will take long time for a school to form favorable learning atmosphere. Of course, this needs joint efforts of teachers and students.

\subsubsection{Changes of students' overall learning style}

It seems difficult to evaluate teaching quality of college English teacher. Firstly, there is no written uniform evaluation system. Students' English result cannot serve as a convictive index. Teaching quality of English teachers in middle schools can be roughly reflected in final examination of the class or English performance in college entrance examination. In colleges, students' learning modes are not all the same. Learning environment is freer. Students' self-study ability is stressed. The channels for students to gain English knowledge are wider. Moreover, except final examination, there is basically no English examination in a semester. Therefore, students' English performance has no too strong persuasion during evaluation of teachers' work. Besides, college students can be regarded as half-social persons. They have their own ideas and social circle. Teachers impossibly infuse their views to students easily. In this aspect, teachers' authority greatly reduces.

\subsection{Internal factors}

Internal factors mainly come from teachers' internal causes and are related to teachers' ability, professional quality and working experience. Now that efficacy sense is a satisfaction degree for teaching work, it certainly varies from person to person. Generally, optimistic people have high efficacy sense, while pessimistic people may have relatively low efficacy sense.

2.2.1 Specialty accomplishment and teaching ability of college English teachers

Generally speaking, college English teacher with high education background will have strong specialty accomplishment and rich knowledge reserve and thus can cope with taking tasks easily. 
Thus, their efficacy sense is high. Of course, a teacher owning rich knowledge does not mean he can successfully infuse knowledge to students. This requires teachers owning very strong teaching ability. Teachers with strong teaching ability can not just control heavy teaching tasks and cultivate students' interest in English, but also well communicate with students. Such teachers naturally have strong efficacy sense. In addition, awards gained by teachers in the teaching process and successful cases also promote improvement of efficacy sense. In turn, the latter promotes improvement of teaching quality. The improvement of teaching ability can boost with the increase in teaching years. Rich experience accumulated in teaching process, communication skills and the ability to cope with emergencies in classroom can improve. For teachers, it is also a process of accumulating efficacy sense. Therefore, highly educated English teachers or teachers with foreign study experience and English teachers with rich experience have relatively strong efficacy sense.

2.2.2 Lack of effective pre-pose and on-the-job training

Colleges have higher recruitment requirements for teachers than junior and senior high schools and require master's degree or above. But, this does not represent efficacy sense of English teachers in colleges is higher than that in junior and senior high schools. On the one hand, enrollment expansion for postgraduates makes overall level of postgraduates drop. High academic degree does not represent high teaching ability. On the other hand, although non-normal university students also gain Teacher Certification, theoretical pedagogy and psychology cannot make sure teachers are able to face possible emergencies in teaching process. Without systematical pre-post training or on-the-job training, teachers will often doubt their ability in the face of education failure and lead to low efficacy sense.

\section{Strategies to improve teaching efficacy of college English teachers}

\subsection{External effective support}

\subsubsection{Social support}

Social support can obviously boost efficacy sense. Social attention to English can make college English teachers feel significance of their work. But it will take long time for the society to improve attention degree. After all, change of the whole society cannot be accomplished in an action. So, improvement of efficacy sense of college English teachers needs the efforts of the whole society.

\subsubsection{School support}

Compared with social support, school support has more practical significance, stronger operability and more obvious effects in a short time. The improvement of school support can be made from the following aspects:

(1) Create harmonious campus environment. From the perspective of sustainable development, it is quite necessary to create harmonious campus environment. Harmonious campus environment can bring students with joyful mood and improve teachers' teaching feeling. Furthermore, reasonable teaching hardware equipment is essential, such as audio-visual classroom and multimedia classroom. Traditional verbal teaching cannot meet the needs of current teaching tasks. Multimedia teaching is current mainstream. Especially, audio-visual classroom can ensure listening and speaking class quality. Currently, the difficulty of English study is not writing, but listening and speaking. Smooth implementation of listening and speaking class also guarantees mutual exchange and communication between teachers and classmates.

(2) Enhance teaching management. Teaching management is an indispensable part of higher education. Colleges' teaching management department should enhance attention to and management of English teaching, urge English teachers to do better.' Teaching management department should arrange teaching tasks for teachers rationally according to their specific situations. For teachers with insufficient experience, teaching management department should reduce their workload to the greatest extent, but teaching quality should be guaranteed. Colleges should frequently organize teaching competitions for young teachers and encourage new teachers to participate. This also provides a platform for teachers to share experience and communicate ${ }^{[5]}$. Besides, tutorial system for young teachers is also a good choice. For instance, a college in Wuhan stipulates that new English teachers of the college must learn together with students in the class of 
supervisors with rich experience for a half year before they formally take up the post. In this way, they can not only deeply know students' ideas, but also absorb teaching experience of excellent teachers. This has obvious effects for improving efficacy sense of new English teachers.

3.2 Capacity improvement

\subsubsection{Training and further studies}

The society is developing and making progress. The requirements for teachers also develop and advance. College English teachers should not just make efforts to accumulate successful teaching cases, but also regularly receive training and further studies to enrich them. In current society, the speed of knowledge update is very fast. Facing increasingly young students, teachers must keep up with the era and make sure their knowledge does not fall behind to keep pace with thinking of young people. Necessary training and further studies have positive promotion functions for teachers' teaching and scientific research. Learning successful teaching cases, mastering diversified teaching methods and improving teaching skills can enhance teachers' teaching efficacy.

3.2.2 Combination of teaching tasks and students' actual needs

In current college English teaching, apart from students majoring in English, English learning purpose of most students is to pass CET-4 and CET-6. Thus, to improve students' learning interest, combination of teaching tasks with CET-4 and CET-6 will gain more obvious teaching effects. For example, when a new English teacher in South-Central University for Nationalities replaced the previous teacher to teach English in the second semester, he combined course contents and CET-4 and CET-6 to teach writing and reading skills from paper writing and article reading. Finally, more than half students in the whole class passed CET-6. The mean score in the final examination was much higher than that in the last semester. Such success can undoubtedly increase efficacy sense of new English teachers. Although college English teaching contents are wide, it is hard to arouse students' learning interest. For example, extensive reading course in college English teaching tasks is basically of no use. It is much inferior to the attraction of a movie. So, stipulation of teaching contents and teachers' teaching should combine students' actual needs.

\section{Conclusions}

Abstractly speaking, efficacy sense refers to one's confidence in the work and spiritual outlook in the face of challenges. Specifically speaking, it is individual self-regulator or a kind of prediction ability. College English teachers should effectively grasp efficacy principle, apply it in their teaching and position individual expectations rationally, firm the confidence in the task and cope with tasks with positive mentality.

\section{References}

[1] [American] Bandura, Self-efficacy: control implementation [M]. Translated by Miao Xiaozhun et al., Shanghai: East China Normal University Press, 1999

[2] Hong Xiumin, Pang Lijuan, On essence, structure and features of self-efficacy of teachers [J]. Science of Education, 2006, (4): 45-46

[5] Li Ye, Liu Huashan, Teacher efficacy and its effects on teaching behaviors [J]. Educational Research and Experiment, 2010, (1): 50-55

[6] Yu Guoliang, Luo Xiaolu, On teachers' teaching efficacy and relevant influencing factors [J]. Journal of Beijing Normal University (Humanities and Social Sciences Edition), 2011(1) 